\title{
BIM 技术在装配式建筑全寿命周期中的应用
}

\author{
周 晖*
}

上海建科工程咨询有限公司, 上海 200032

\begin{abstract}
摘 要: 装配式建筑结构已经成为现代建筑工程建设的主要形式, 相比传统结构其在施工以及管理上具有更大优势, 不仅工艺简单、 施工效率以及安全性高, 工程建设的经济效益也更高, 因此得到广泛地应用。将BIM技术应用到装配式建筑全寿命周期中, 可以对设计、生 产、施工以及运维各个阶段工作的开展提供技术指导, 真正实现工程建设过程的系统化、专业化以及高效化, 能够通过统一平台更及时的 发现存在的问题，加强不同专业之间的联系沟通，在第一时间采取措施解决问题，保证工程以最少的资源达到预期施工效果。
\end{abstract}

关键词: BIM技术; 装配式建筑; 全寿命周期; 施工管理

\section{Application of BIM Technology in the Life Cycle of Prefabricated Buildings}

\author{
Hui Zhou* \\ Shanghai Jianke Engineering Consulting Co., Ltd., Shanghai 200032, China
}

\begin{abstract}
Prefabricated building structure has become the main form of modern construction engineering construction. Compared with traditional structures, it has greater advantages in construction and management. The process is simple, the construction efficiency and safety are high, and the economic benefits of the project construction are great. Therefore, it is widely used. The application of BIM technology to the whole life cycle of prefabricated buildings can provide technical guidance for the work in various stages of design, production, construction, operation and maintenance. The systemization, specialization and efficiency of the engineering construction process are truly realized. Existing problems can be discovered timely through a unified platform. The communication between different professions was strengthened, and measures were taken to solve problems in the first time to ensure that the project achieved the expected construction effect with minimal resources.
\end{abstract}

Keywords: BIM technology; prefabricated building; full life cycle; construction management

\section{一、前言}

面对快速发展的建筑行业, 各项施工技术与施工工艺在不断地更新, 目前装配式建筑规模正在持续不断地扩大, 对应的技术工艺也日益 成熟。与传统建筑相比, 装配式建筑现场作业更加简单, 各结构按照设计要求在工厂加工完成, 运输到场后进行组配安装即可, 施工效率 更高, 且施工成本更低。而BIM技术在装配式建筑中的应用, 可以进一步来加快施工进度, 对工程整个建设周期提供技术指导, 加强设计、 生产、施工以及运维各阶段的联系, 并以同一平台为支持, 不同专业项目之间相互配合, 达到最佳施工状态, 为施工质量、进度以及成本 等各方面的控制管理提供可靠保障，提高工程建设综合效益。

\section{二、装配式建筑特点}

装配式建筑与传统建筑相比, 最大的差别在于其是在现场完成预制构件的装配施工, 施工周期更短, 且成本更低, 可进一步提高工程建 设经济效益。为满足社会发展要求, 建筑工程规模越来越大, 且出现了大量的高层以及超高层建筑, 存在大量的高空作业, 所需现场人力 资源更多。

相比来讲, 装配式建筑工程现场作业优势更大, 专业人员可通过机械化操作完成各构件组装, 施工效率以及安全性均得到了提升。同 时, 因为人力资源的减少，相应的成本投资也有所减少。

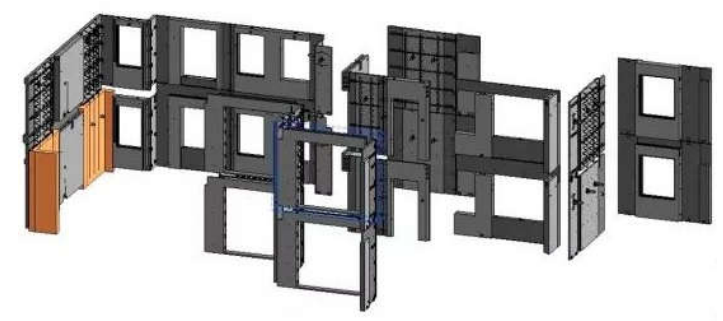

图1 装配式建筑特点

装配式建筑所有构件均是在工厂预制生产完成, 然后运输到现场作业, 这样就大大降低了现场施工噪音, 避免了现场飞尘, 对环境带来 的影响大大降低, 环保效果更强 ${ }^{[1]}$ 。另外, 钢模板、木模板还可以进行循环使用, 减少资源的浪费, 以及成本投人更低。对于传统建筑工程

\footnotetext{
*通讯作者: 周晖, 1981 年 12 月, 男, 汉族, 上海人, 现任上海建科工程咨询有限公司高级顾问, 本科。研究方向: BIM 在工程建设中的应用。
} 
来讲，现场作业很大程度上受限于气候环境，包括低温降雨天气不允许作业，会对施工进度造成一定影响。

而装配式建筑大部分作业可以在工厂或仓房内完成，外墙板与预制梁柱则是运输到场后直接安装即可，外部气候条件对施工作业产生的 影响较小。装配式建筑具有众多优势, 更贴合绿色建筑的发展理念, 而想要进一步提高工程施工质量, 则可以将BIM技术作为支持, 对整个 工程建设全周期进行管理，为每项工作的开展提供可靠的技术指导，减少常见问题的发生。

\section{三、BIM 技术在装配式建筑中应用优势}

BIM技术作为数据信息仿真，具有模拟性、协调性以及可视化的特点。

\section{(一) 模拟性}

并不仅是对建筑模型进行模拟设计, 同时能够实现对无法在真实世界操作的事物进行模拟。在建筑工程设计阶段, 可以完成各项内容的 模拟, 包括节能模拟、日照模拟、热能传导模拟等 ${ }^{[2]}$ 。而在施工阶段则可以根据施工组织来对现场施工情况进行模拟, 进而能够为实际作业 提供指导。

\section{（二）协调性}

建筑工程涉及的专业内容非常多, 存在很强的系统性与专业性, 想要达到与设计一致的施工效果, 就需要不同专业之间保持高效的配 合。BIM技术可以通过统一的平台来实现不同专业之间的密切联系, 所有专业均可以在平台上获取所需信息, 真正做到信息的共享, 实现不 同部门的有效沟通，及时就存在的问题进行协商处理，为正式施工打好基础，避免施工阶段的变更发生，提高施工综合效率 ${ }^{[3]}$ 。

\section{(三) 可视化}

BIM技术的应用可以实现工程管理的可视化, 即在工程中可以将传统的二维图纸转变为三维立体形象, 为工作人员提供更加直观的图纸 形象, 进而能够更全面的掌握工程施工情况。将BIM技术应用到装配式建筑全寿命中, 无论是设计、生产、施工以及运营等各可以在可视化 状态下展开管理, 为工程质量以及进度管理提供了可靠保障 ${ }^{[4]}$ 。

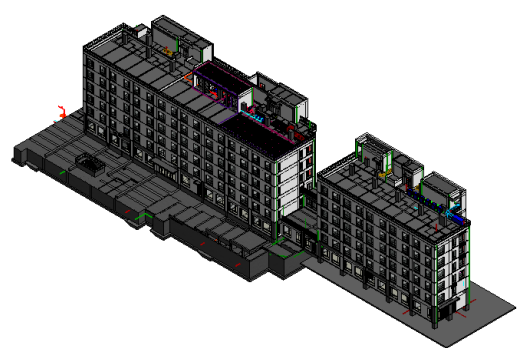

图2 建筑+结构+机电

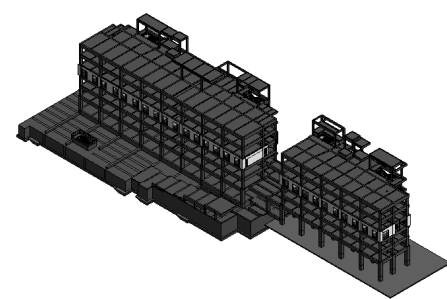

图4 结构

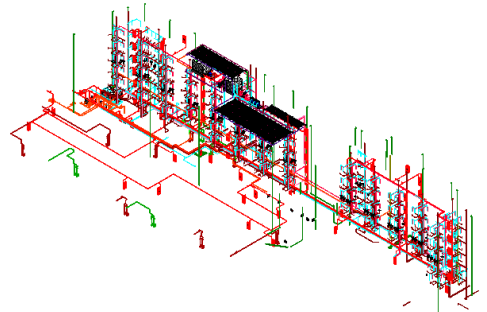

图6 机电-给排水

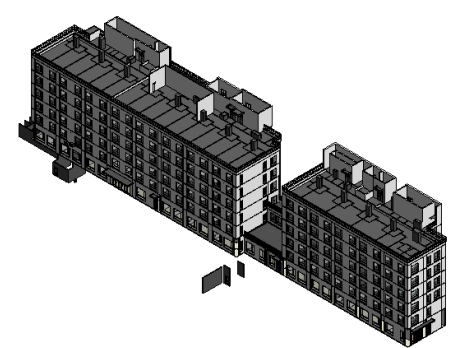

图3 建筑

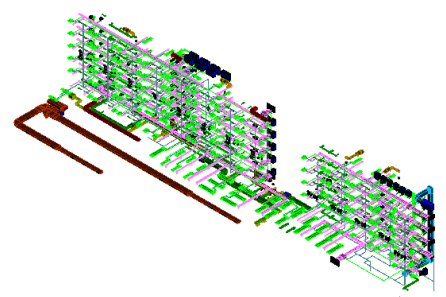

图5 机电-暖通

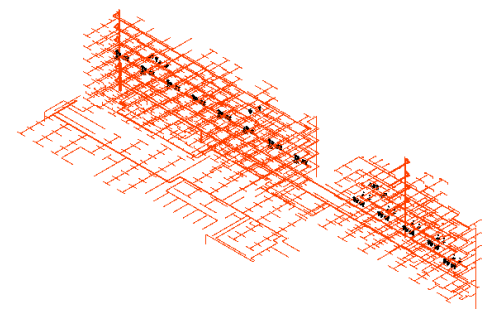

图7 机电-消防

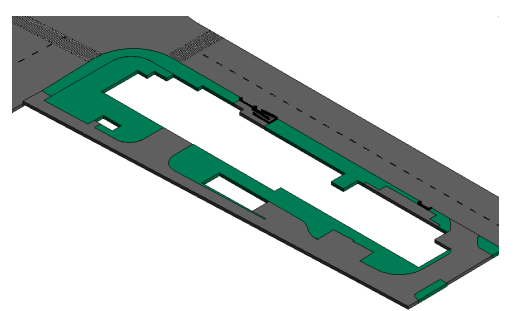

图8 小市政 
基于BIM技术的特点, 将其应用到装配式建筑全寿命周期中, 可以全面获取建筑工程所有信息数据, 并在内部实现信息共享, 所有部门 均可以获取所需信息, 避免因信息孤岛而造成的合作不畅问题, 大大减少了后期变更的可能性。BIM技术在建筑工程中的应用, 是作为一种 数字化工具存在, 以参数化模型来对各类信息进行归纳集合, 并实现数据信息的传递共享, 为工程管理提供信息支持, 以便于可以根据建 筑信息实时作出应对 ${ }^{[5]}$ 。BIM技术的存在, 使得多方单位加强了协作, 提高了生产效率, 减少了系列不必要的问题的产生, 为工程进度以及 成本控制创造更为有利的条件。

\section{四、BIM 技术在装配式建筑全周期中应用}

(一) 设计阶段应用

1. 提高设计图纸质量

建筑工程的建设效果如何, 很大程度上取决于前期的规划设计, 规划决定了建筑的定位, 而设计则关系着建筑的建造方向。BIM技术建 立有信息数据库，且建筑模型中对所有构件属性进行了说明，可以直接通过搜查构件属性来获得构件类型、尺寸以及材质等所有参数信息， 为工程设计施工提供依据。尤其是可针对类似板块进行合并及归类, 增加重复率, 提高施工效率, 较少开模种类 ${ }^{[6]}$ 。相比传统的二维设计图 纸, BIM技术实现了建筑的三维设计, 设计人员能够更加直观的观察到工程结构, 如果需要对其中的参数进行修改调整, 则整个模型会自动 进行调整更改, 完全避免了因图纸间错、漏造成的信息不一致问题的发生, 降低了设计变更的可能性, 提高了工程设计综合效率。装配式建 筑存储信息种类的规范并不统一, 基于此应用BIM技术来对装配式建筑构件进行分编码, 设计BIM构件分类与构件编码体系, 为装配式建筑 全寿命周期管理提供可靠支持。并且，BIM技术的应用，还可以检测及消除项目施工方工作过程中的碰撞，强化项目执行阶段的协同性。

2. 减少设计误差

通过BIM技术可以实现所有建筑预制构件的优化设计, 包括构件几何尺寸、内部钢筋直径、间距、钢筋保护层厚度等, 提高每项参数设 计的准确性, 为精细化生产的实现打好基础, 同时也为后期现场安装的提供了便利, 避免因为设计不标准而造成装配偏差过大。另外, 应 用BIM技术还可以对模型进行碰撞检测, 可以发现设计中隐藏的问题, 对存在碰撞问题的部分进行相应修改, 相比传统2D管线综合对比, 三维管线综合设计优势更加明显, 以免在实际组装时遇到问题进行变更与返工, 避免了工期延误 ${ }^{[7]}$ 。在设计阶段, 通过BIM技术的可视化特 点, 可直接观察确认不同构件之间的契合度, 确定节点连接的可靠性, 从设计阶段就排除不合适的可能性, 将误差控制到最小, 以免延误 工期和产生不必要的成本。

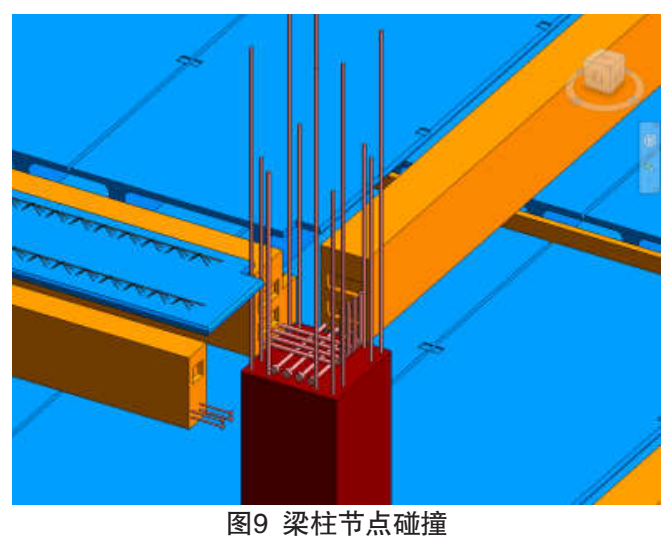

3. 加强成本控制

除了对构件设计提供支持以外, BIM技术的应用还能够进一步优化工程成本的控制。以往工程造价设计阶段需要花费大量的时间来进行 工程量的统计, 且容易出现人为失误。而BIM技术的应用, 则完全可以通过系统数据来进行分析, 不仅能够降低工作强度, 还可以避免人为 失误, 使得造价精度得到进一步提高。尤其是基于BIM技术工程设计得到了优化, 避免了构件冲突、碰撞等问题, 大大消除了相关方面的成 本投人。在针对装配式建筑设计时, 首先需要明确项目随着时间维度变化的 $5 \mathrm{D}$ 模型, 确定工程施工所需的各种材料数量及材料对应的定额 信息，并应用广联达、鲁班等算量软件与模型对接，计算得到材料造价、人工等信息，基于此来实现工程施工成本的管理。

(二) 制作阶段应用

1. 优化制作流程

生产阶段对装配式建筑工程建设也有着重大影响, 必须要提高对其的重视, 作为关联设计与施工阶段的重要环节, 需要采取措施加强管 理。相比通过二维图纸间接获取设计信息, 直接通过BIM模型来获得各构件数据可靠性与精确性更高, 能够有效避免因为读图错误产生的生 产误差。如果在生产阶段构件尺寸产生错误, 则会导致后续的现场安装完全无法进行。目前可以通过BIM技术直接将建筑模型的各项信息数 据发送给厂家, 获取所有构件产品的尺寸、材料、钢筋等级等系列参数, 确保了生产加工的准确性, 同时还可以提高预制构件生产的自动 化水平 ${ }^{[8]}$ 。

2. 指导模型试制

可对建筑构件进行拟生产, 以及预拼装, 以一种更加直接的方式将建筑模型展示出来, 确认预拼装过程的施工工序与作业进度, 为实际 施工提供一定指导, 保证工程施工进度与质量。并且通过预拼装, 可以及时发现其中存在的问题与不足, 更好的检验设计方案的合理性, 
为工程的高效化施工提供支持。

(三) 施工阶段应用

1. 施工过程模拟

应用BIM技术对装配式建筑施工过程进行模拟和仿真, 可以为实际施工提供有效的技术指导, 提高各环节操作的协调性, 为施工流程与 作业方案的调整提供支持，确保了所有构件安装的准确性与有效性。同时，基于BIM技术还可以实现现场环境的科学布置，完成垂直机械、 构配件以及临时设施的合理安排, 为道路运输创造了有利条件, 更便于预制构件运输到场, 不仅可以降低二次搬运的难度, 同时也可以降 低多次搬运对预制构件造成的损坏 ${ }^{[9]}$ 。以及合理的布置位置, 为吊装提供了便利, 提高现场施工效率，加快实际装配进度。另外，基于BIM 技术的可视化特点, 来实现技术交底, 提高了技术交底的直观性, 提升了不同部门之间沟通的有效性, 即便是遇到问题也可以以最短的时 间来协商解决，将损失控制到最小。

\section{2. 材料动态管理}

通过BIM技术还可以对施工材料进行动态管理, 即提前对现场各条件进行分析研究, 制定科学的计划, 确定构件采购上限, 以满足实际 施工需求为基础，快速测算不同施工阶段预制构件的需求量 ${ }^{[10]}$ 。同时，完成各项准备工作，做好所有材料的规划布置，尽量排除不同类型 材料以及设备之间的相互干扰，减少二次搬运与堆放过多问题，为现场施工创造最为有利的条件。同时，还可以结合施工进度来对材料进 行灵活调整，保证为不同区域的构件需求提供保障。

3. 进度与质量管理

施工质量和施工进度是影响建筑工程建设综合效益的关键，同时也是施工管理的核心要点。以BIM技术为支持，对整个施工技术进行科 学分析, 并创建4D施工模型, 对现场施工进度与质量进行动态跟踪。将收集反馈的实际信息与计划数据进行比对, 计算两者之间的偏差, 及时采取措施进行调整, 解决存在的各种突出问题, 争取达到最优化的施工条件 ${ }^{[11,12]}$ 。通过BIM5D的应用, 将全专业模型作为载体, 实现工 程施工全过程中进度、合同、成本、质量、安全、图纸以及材料等各方面信息, 作为项目管理的数据支持, 进一步实现精细化管理，确保 每一项决策制定的科学性与可行性，减少施工变更，合理控制工期，提高质量以及成本管理效率。

\section{五、结束语}

将BIM技术应用到装配式建筑的全生命周期中优势巨大，可进一步实现设计、生产、施工以及运维各阶段管理的优化，在提高工程施工 质量与施工效率的同时，获取最高经济效益，提高工程建设综合效果。

\section{参考文献:}

[1]张浩.BIM技术在装配式建筑全寿命周期中的应用[J].建材与装饰, 2019(29):33-34.

[2]王成元,徐理,曾海明,郭秋兰,廖菲菲,蔡运芳.BIM技术在装配式建筑全寿命周期中的应用 [J].合作经济与科技, 2019(16):128-130.

[3] 曾浩, 黄雯婷.BIM技术在装配式建筑全寿命周期中的应用研究 [J]. 绿色环保建材, 2019(01):190+192.

[4]许㻇.浅析BIM技术在装配式建筑中的应用价值[J].中国住宅设施, 2018(07):70-71.

[5]刘莹莹,张树懿.BIM技术在装配式建筑全寿命周期中的应用[J].山西建筑, 2018,44(18):217-219.

[6]席慧.BIM技术在装配式建筑全寿命周期中的应用分析[J].科技创新导报, 2018,15(12):183-184.

[7]邱忠吴,叶航.BIM与RFID技术在装配式建筑全寿命周期管理中的应用研究[J].建材与装饰, 2018(07):136-137.

[8]张迎春,潘捷.BIM技术在装配式建筑全寿命周期中的应用研究[J].中国住宅设施, 2017(03):47-49.

[9]蔡敏华.BIM技术在装配式建筑全生命周期中的应用[J].门窗, 2017(07):241.

[10]周冰洁.BIM技术在装配式建筑中的应用[J].中国住宅设施, 2017(06):12-13.

[11]白庶,张艳坤,韩风,张德海,李微.BIM技术在装配式建筑中的应用价值分析[J].建筑经济, 2015,36(11):106-109.

[12]张家昌,马从权,刘文山.BIM和RFID技术在装配式建筑全寿命周期管理中的应用探讨[J]. 辽宁工业大学学报(社会科学版), 2015,17(02): $39-41$. 